Commentary

\title{
Disability Policy Must Espouse Medical as well as Social Rehabilitation
}

Andrew J. Haig ${ }^{1,2}$

${ }^{1}$ Department of Physical Medicine and Rehabilitation, University of Michigan Health System, 1500 E. Medical Center Drive, Ann Arbor, MI 48109, USA

${ }^{2}$ International Rehabilitation Forum, Ann Arbor, MI 48103, USA

\section{How to Cite this Article}

Haig, A. J. (2013). Disability Policy Must Espouse Medical as well as Social Rehabilitation. Social Inclusion, 1(2), 136-138.

\section{Acknowledgement}

This Commentary was published by Librello, Social Inclusion's former publisher.

\section{About the Journal}

Social Inclusion is a peer-reviewed open access journal which provides academics and policy-makers with a forum to discuss and promote a more socially inclusive society. The journal encourages researchers to publish their results on topics concerning social and cultural cohesiveness, marginalized social groups, social stratification, minority-majority interaction, cultural diversity, national identity, and core-periphery relations, while making significant contributions to the understanding and enhancement of social inclusion worldwide.

www.cogitatiopress.com/socialinclusion

\section{Editor-in-Chief}

Professor Ulf R. Hedetoft, Faculty of Humanities, University of Copenhagen, Denmark

\section{Managing Editor}

Mr. António Vieira, Social Inclusion, Cogitatio Press, Portugal 


\title{
Disability Policy Must Espouse Medical as well as Social Rehabilitation
}

\author{
Andrew J. Haig ${ }^{1,2}$ \\ ${ }^{1}$ Department of Physical Medicine and Rehabilitation, University of Michigan Health System, 1500 E. Medical \\ Center Drive, Ann Arbor, MI 48109, USA \\ ${ }^{2}$ International Rehabilitation Forum, Ann Arbor, MI 48103, USA \\ Submitted: 23 September 2013 | In revised form: 19 December 2013 | Accepted: 20 December 2013 | \\ Published: 27 December 2013
}

\begin{abstract}
A confident statement in Social Inclusion by Mannon and MacLacLan that disability is not a health problem places doubt on the rationale of their otherwise well-written research agenda for disability studies. Both by definition and in practice disability is in part about the impact of health on a person's functioning. The consequence of this misperception among social policy makers is a decreased emphasis on the resources and research needed to build medical rehabilitation programs. This is especially true in lower resource countries where naive inclusion of medical rehabillitation within community based rehabilitation strategies has resulted in fewer resources and less expertise to deliver the distinctly different, and well validated services of a medical rehabilitation team. Any rational research agenda on disability must focus on disease and medical rehabilitation as well as the psychological, social, and environmental factors discussed in this article.
\end{abstract}

Keywords: disability; health; social inclusion

The proposal of a research agenda for an entire field of academic inquiry as large as 'disability' is a daunting task. Mannon and MacLaclan's thoughtful review attempts this, however their introductory premise that 'disability is not a health problem' is ill-conceived [1]. Perhaps because of this erroneous understanding the research agenda does not separate medical rehabilitation as an important and distinct part of the discussion.

As a clinician/scientist I'm less concerned about the semantics than some of my social science colleagues. However in this case they are of consequence. The failure to leap tall buildings in a single bound (a feat greatly desired by many 10 year old consumers who have watched Superman movies, and is not associ- ated with health) is a dis-ability, but does not fit into our rational discussion. The inability to walk due to spinal cord injury is squarely within the scope of disability as we know it because we know that walking is possible for some people but not others. The term disability is inextricably intertwined with other terms describing the rational expectations of human existence, including disease (dis-ease) and illness. Disability is about the consequences of human illness. Not exclusively so. But undeniably true. It is in fact a health problem.

I must first agree that health and medicine are not all of disability. The International Classification of Function model makes sense: its familiar graphic summary 
acknowledges personal factors, environmental factors, activities and participation [2]. However it is wrong to trivialize the other two boxes on that familiar diagram. Understanding and optimizing 'health conditions' and 'body functions' is largely the work of scientists and professionals related to medicine.

There appears to be a fear or avoidance of medicine and 'medicalization' is often a derogatory term in the world of academic social scientists who deal with disability. This negativity may be based in the valid and heroic struggle to stop society from defining people by their disabling medical conditions, and it remains important to confront the parternalistic attitudes of some healthcare providers towards people with disability. An unintended artifact of this fight is that some social academics avoid the fact of disease like the plague (yes, I said that...). One aspect of medicalization is the defining of people as diseases. That is bad. However another aspect of medicalization is the defining of diseases as diseases, and the subsequent systematic and scientific process by which the diseases and their impact on ability are ameliorated. (yes, only if the person with disability wishes... fear not, disability rights advocates). That's good. Where social scientists have overflow anxiety at the mention of the word 'medical' they do not see the world clearly.

Perhaps because the authors of the policy agenda downplay any medical aspect of disability, their framework does not separate medical rehabilitation from either community based rehabilitation (CBR) or access to general medical care. Since the term CBR has been used broadly and nonspecifically in the past, It is important to set boundaries around the term CBR in our discussion. CBR involves care and empowerment of people in the natural community setting, such as home and work. To include hospitals and clinics in the definition, as some apologists might do, would imply that community-based liver transplantation and community-based coronary artery bypass surgery are also part of our lexicon. The work of medical professionals based in medical facilities providing rehabilitation services is not CBR.

Medical rehabilitation is not curative medicine either. In my hospital rounds today, I am providing medical rehabilitation to a nice woman who cannot walk after a bone marrow transplantation for cancer. I will not cure her. I will seek out the multiple causes of her disability (perhaps a combination of steroid myopathy, avascular necrosis of the femoral head, major depression, pain and irrational lack of hope). If we're lucky I'll find a reversible cause and then will ask my colleagues who treat these diseases to cure her. Probably not. More likely I will begin prescribing medications to control symptoms, assistive devices, and other rehabilitation medical procedures. I will call on my expert colleagues in physiotherapy, rehabilitation nursing, and occupational therapy to assess her. Together the team will meet to concur on functional goals, time frames, and coordinated plans aimed at both discharge from the hospital and 6 months after discharge. Then we will go to work, using our diverse, but highly specialized clinical education and experience, in an architecturally distinct medical rehabilitation ward, with specialized medical technology, to help this woman become independent at home. At some point there may well be collaboration with communitybased rehabilitation resources. We may instruct family members, ask the local church to help build a wheelchair ramp, and look to home health agencies to continue the transitional process in the home. Medical rehabilitation involves the use of medical knowledge to accomplish the functional and quality of life goals of people whose diseases have caused them to have a disability.

The well-trod path of medical rehabilitation involves intensively trained clinicians, specialized facilities and expert coordination of a multidisciplinary team. Medical rehabilitation defines the careers of tens of thousands of physicians who train 4-6 years after their medical doctorate degree to obtain specialist certifications in Physical Medicine and Rehabilitation. It includes hundreds of thousands of allied health professionals including physiotherapists, occupational therapists, rehabilitation specialist nurses, rehabilitation psychologists and social workers, speech-language pathologists, prosthetists, orthotists, rehabilitation engineers and others whose training is medical and whose work is medical in nature. Despite this massive professional presence and the billions of square meters of hospital and clinic space that these people work in, figure 2 of the policy article places the work of all of these people vaguely among 25 other boxes in 'the community based rehabilitation matrix'. I think my patient will die if I attempt to do the rehabilitation in the community. Hospitals and clinics are not 'the community'. My work today is not community based. It is rehabilitation.

Medical rehabilitation is ubiquitous in the industrialized world-and completely unavailable to people who live in many low resource regions-even the wealthy people [3]. This fact can be traced precisely to the failure of social scientists and policy makers to consider medical rehabilitation as both critical and distinct from community-based efforts and general medical care. Years ago policymakers decided that there were so many disabled people that the high-quality medical rehabilitation they would wish for their own family members could not reach them all. The consequence was a policy of promoting CBR without a balanced advocacy for medical rehabilitation. CBR, as the authors point out, is still an unproven policy after 40 years of World Health Organization promotion, hundreds of millions of dollars of investment and the presence of countless local programs. In contrast, medical rehabilitation as I provided to my patient today has been demonstrated through myriad high-quality prospective randomized, controlled trials to be superior to less intensive management in decreasing disability, improving 
independence, and improving long term quality of life for people with any number of seriously disabling disorders, ranging from stroke to brain injury to amputation to cancer to backaches to birth disorders.

This imbalance is not an artifact of benign neglect. It is the result of faulty paradigm, conflict of interest, and false impression. Susan Buehl challenged the western sociologist's paradigm, her argument summarized succinctly by Grech:

\begin{abstract}
"overall, within dominant models of disability, 'specialist knowledge', she argued, is viewed as a poisoned chalice that is made so in practice by ignoring the value that skilled knowledge can contribute to breaking down barriers for families by providing support at the micro level..." [4]
\end{abstract}

Where there is competition for limited resources, important conflicts of interest feed CBR at the expense of medical rehabilitation. One is unequal representation of the populations served. CBR is often advocated for by people who live with disability in the community and who might benefit from jobs, schooling, or access; and who have survived the early phase of their disabling health problem. In contrast, the population that benefits from medical rehabilitation is typically in an uncertain transient state and naïve to the issues. I was about to use the words 'in shock' here, but I fear that my sociology colleagues will underestimate this as merely some existential crisis. These people are emotionally traumatized. But they can't attend the local hearing on disability rights because they're on morphine and septic. Or they will not be allowed on the plane to the WHO meeting in Geneva because their IV poles won't get through

\section{References and Notes}

1. Mannan $H$, MacLaclan M. Disability and Health: A Research Agenda. Social Inclusion. 2013;1(1):3745.

2. World Health Organization. International Classification of Functioning, Disability and Health. Available from: http://www.who.int/classifications/icf/en (accessed on 19 December 2013).

3. World Health Organization. World Report on Disability. Available from: http://www.who.int/disabilities/world_report/2011/en/index.html (accessed on 16 August 2013).

4. Grech S, Goodley D. Doing disability research in the majority world: An alternative framework and the quest for decolonising methods. Journal of Human Development, Disability, and Social Change. 2012;19 (2):43-55.

5. Haig AJ, Im J, Nelson VS, Adewole A, Krabak B. The Practice of Physical Medicine and Rehabilitation in Africa and Antarctica: A White Book or a Black Mark? security. The underrepresentation of the needs of people with acute illness in the disability rights conversation is an injustice.

Politicians and the media feed this bias. The voice of disability rights is much more often the welldressed, cognitively intact young person in a sports wheelchair who has the skill and desire to rise through the politics of the disability community. Not the drooling, drugged, bloody, moaning and emotionally devastated person who arrived on the trauma ward last night. With limited resources people who are beyond the acute phase sometimes get what they want at the expense of people who desperately need medical rehabilitation.

The consequences of this failure to recognize medical rehabilitation as distinct and critical are far reaching. On one end of the spectrum sub-Saharan Africa has only 6 Physical Medicine and Rehabilitation physicians and no training programs [5-10]. On the other end, the woman I saw today at a world-class cancer center did not receive a medical rehabilitation consultation for over 2 weeks because the doctors and nurses felt responsibility only for treating the disease, not the disability.

Until theoreticians, editorialists, and policymakers recognize the distinct and critical place of medical rehabilitation in the scheme of disability studies, neither African ministries of health nor American sub-specialist training programs will take responsibility to address the medical rehabilitation needs of the people they serve. It is critical that this 'research agenda' should change its paradigm to separate medical rehabilitation as a distinct and important component of disability science. Because disability is also a health problem.

Journal of Rehabilitation Medicine. 2009;41(6):401405.

6. Haig AJ, Im J, Nelson VS, Adewole A, Krabak B. The Practice of Physical Medicine and Rehabilitation in Africa and Antarctica: A White Book or a Black Mark? PM \& R. 2009;1(5):421-426.

7. Haig AJ, Im J, Nelson VS, Adewole A, Krabak B. The Practice of Physical Medicine and Rehabilitation in Africa and Antarctica: A White Book or a Black Mark? European Journal of Physical \& Rehabilitation Medicine. 2009;45(2):185-191.

8. Haig AJ, Im J, Nelson VS, Adewole A, Krabak B. The Practice of Physical Medicine and Rehabilitation in Africa and Antarctica: A White Book or a Black Mark? Disability and Rehabilitation. 2009;31(13):1031-1037.

9. Haig AJ, Im J, Nelson VS, Adewole A, Krabak B. The Practice of Physical Medicine and Rehabilitation in Africa and Antarctica: A White Book or a Black Mark? Chinese Journal of Rehabilitation Medicine. 2009;24 (5):385-389.

10. Simultaneous publication with consent of all journals. 